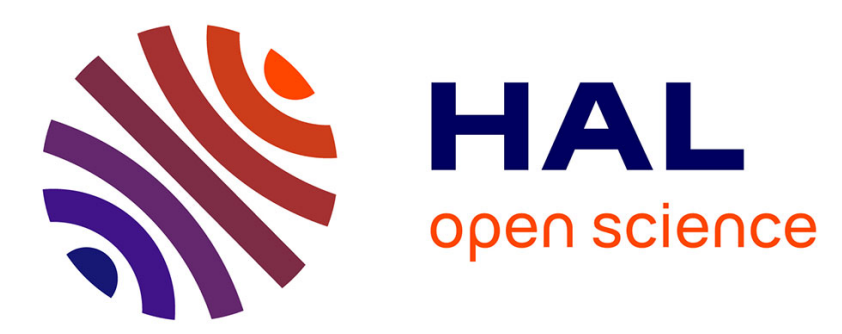

\title{
Adverse Selection in the Environmental Stewardship Scheme: Does the Higher Level Stewardship Scheme Design Reduce Adverse Selection?
}

\author{
Emmanuelle Quillérou, Robert W. Fraser
}

\section{- To cite this version:}

Emmanuelle Quillérou, Robert W. Fraser. Adverse Selection in the Environmental Stewardship Scheme: Does the Higher Level Stewardship Scheme Design Reduce Adverse Selection?. Journal of Agricultural Economics, 2010, 61 (2), pp.369-380. 10.1111/j.1477-9552.2010.00240.x . hal-01954577

\author{
HAL Id: hal-01954577 \\ https://hal.science/hal-01954577
}

Submitted on 18 Feb 2019

HAL is a multi-disciplinary open access archive for the deposit and dissemination of scientific research documents, whether they are published or not. The documents may come from teaching and research institutions in France or abroad, or from public or private research centers.
L'archive ouverte pluridisciplinaire HAL, est destinée au dépôt et à la diffusion de documents scientifiques de niveau recherche, publiés ou non, émanant des établissements d'enseignement et de recherche français ou étrangers, des laboratoires publics ou privés. 
Adverse Selection in the Environmental Stewardship Scheme: Does the Higher Level Stewardship Scheme Design Reduce Adverse Selection?

\author{
Emmanuelle Quillérou ${ }^{a}{ }^{*}$ and Rob Fraser ${ }^{b, c}$
}

\begin{abstract}
a Kent Business School, University of Kent, Canterbury, CT2 7NZ, United Kingdom ${ }^{b}$ School of Economics University of Kent, Canterbury, CT2 7NZ, United Kingdom

$c$ University of Western Australia
\end{abstract}

\author{
* Corresponding author \\ E-mail: E.Quillerou@kent.ac.uk
}




\title{
Adverse Selection in the Environmental Stewardship Scheme: \\ Does the Higher Level Stewardship Scheme Design Reduce Adverse Selection? *
}

\begin{abstract}
The Environmental Stewardship Scheme provides payments to farmers for the provision of environmental services based on foregone agricultural income. This creates a potential incentive compatibility problem which, combined with information asymmetry about farm land potential, can lead to adverse selection of land into the Scheme and therefore a less cost-effective provision of environmental goods and services. However, the Higher Level Stewardship (HLS) Scheme design includes some features that potentially reduce adverse selection. This paper studies the adverse selection problem of the HLS using a principal agent framework at the regional level. It is found that, at the regional level, the enrolment of more land from lower payment regions for a given budget constraint has reduced the adverse selection problem through contracting a greater overall area and thus higher overall environmental benefit. In addition, for landscape regions with the same payment rate (i.e. of the same agricultural value), differential weighting of the public demand for environmental goods and services provided by agriculture (measured by weighting an environmental benefit function by the distance to main cities) appears to be reflected in the regulator's allocation of contracts, thereby also reducing the adverse selection problem.
\end{abstract}

Keywords: Adverse selection, agri-environment, Environmental Stewardship, principal-agent, contract JEL codes: D78; D82; H44; Q18; Q58

* Emmanuelle Quillérou is the contact author (E.Quillerou@kent.ac.uk). Both authors are respectively in the Kent Business School and in the School of Economics at the University of Kent, Canterbury, CT2 7NZ, where Rob Fraser is Professor of Agricultural Economics, and also Adjunct Professor of Agricultural and Resource Economics, University of Western Australia. The authors are particularly grateful to Dr lain Fraser, the Associate Editor and two anonymous referees for their helpful comments on previous versions. We would also like to thank Natural England Agri-Environment Team for the provision of data on the agri-environmental schemes, without which this study would not have been possible. 


\section{Introduction}

From 1992, the European Common Agricultural Policy's successive reforms have shifted away from production support by including a parallel agri-environmental policy reflecting the multifunctionality of agriculture. This agri-environmental policy offers payments to farmers for providing environmental goods and services. The main agri-environmental scheme in England since 2005 has been the Environmental Stewardship Scheme, which builds on the baseline cross compliance requirements (Defra, 2005a). It is a nationally-set two-tiered scheme, corresponding to two levels of increasing environmental commitment: the ELS/OELS (Entry Level Stewardship/Organic Entry Level Stewardship) tier with more general requirements (and higher participation), and the HLS (Higher Level Stewardship) tier with more specific environmental requirements and a higher level of environmental commitment (and consequently more limited participation). The ELS tier (along with the OELS, its equivalent for organic agriculture) is based on a whole-farm approach and open to all farmers and landowners, within 5-year contracts (Defra, 2005a). It relies on self-selection by farmers of environmental options from a given 'menu', each option corresponding to a given number of points reflecting the agricultural income foregone (which is nationally estimated) (Defra, 2005a). ELS (OELS) agreements are guaranteed providing farmers meet a 30-point (60-point) target per hectare for a corresponding payment of $£ 30 /$ ha ( $£ 60 /$ ha) (Defra, 2005a).

The second tier or Higher Level Stewardship (HLS) targets more complex types of management and capital work plans (Defra, 2005a, 2005b). Like the ELS, farmers still self-select land management options within a set 'menu' and for fixed per unit payments for each option. However, entry is at the discretion of Natural England (the operating authority), which competitively selects applications using a scoring and threshold mechanism. This is derived from the previous Countryside Stewardship Scheme, and assesses the environmental value provided so as to select contracts providing "good 'value for money' " (Defra, 2005a, 2005b). Scoring of applications is spatially differentiated, based on 159 Joint Character Areas i.e. areas of the English countryside with similar landscape character, each with a specific association of wildlife and natural features (Defra, 2005b). Each Joint Character Area has a corresponding set of environmental key and secondary targets (detailed in specific 'targeting statements') for the management of a variety of features, against which farm applications are scored, with priority given to Sites of Special Scientific Interest (SSSIs) and Scheduled Monuments (Defra, 2005b). Scored applications are then pooled for all Joint Character Areas within the same administrative region (roughly corresponding to the government office regions). The threshold entry decision criterion or cut-off score is then set for all Joint Character Areas within the same administrative region, in relation to the available regional budget, so that all applications with a score above the (budget-determined) regional threshold score are retained for contracting.

The Environmental Stewardship Scheme aims at delivering environmental benefits, but is based on incentive payments typically calculated as an average of the agricultural income foregone by farmers (or 'opportunity cost', OC) and not as the environmental benefit derived from the land entered into the Scheme. Since agricultural income and environmental benefit are not necessarily (spatially) positively correlated (OECD, 2004, Fraser, 2009), the discrepancy between farmer incentives to enter the Environmental Stewardship Scheme based on their individual OC of agricultural production and the government agencies' (Defra and Natural England) objective of paying farmers for an environmental benefit potentially leads to an incentive-compatibility problem (Fraser and Fraser, 2006). In combination with information asymmetries regarding farmer's $O C$ of environmental service provision and land quality, this incentive incompatibility can lead to adverse selection of land for entry into the schemes which therefore reduces the cost-effectiveness of the Scheme and results in a socially suboptimal provision of environmental goods and services (Fraser, 2009). In particular, the potential for adverse selection into the Scheme would be expressed as the lowest agricultural quality land being entered into the Scheme by farmers rather than the highest environmental quality land as targeted by the government. The quasi-market payment for agri-environment provision is thus unlikely to be optimal (compared to a full information situation), and the combination of incentive incompatibilities and information asymmetries is likely to lead to systematic misallocation of taxpayer funding, both within and between landscape regions.

However, while all Environmental Stewardship tiers are likely to be subject to incentive-incompatibility, as will be explained in this paper, this problem is potentially reduced in the case of the HLS both because it includes explicit selection based on environmental benefit criteria and because this selection is subject to a budget constraint. In particular, although farmers with the lowest agricultural OC have the greatest incentive to apply for the Scheme, the selection mechanism means that only farmers assessed as providing higher environmental benefit are admitted into the Scheme, thereby 
potentially reducing the adverse selection problem and increasing the cost-effectiveness of the Scheme. In addition, the operation of the HLS subject to a budget constraint on total payments to farmers encourages the selection of 'low cost' farmers which, where they are providing similar environmental benefits to 'high cost' farmers, will also improve the overall cost-effectiveness of the Scheme. Therefore, this paper focuses on the features of the HLS policy design that operate to decrease the potential for adverse selection, thereby improving the cost-effectiveness of the Scheme ${ }^{1}$.

Most of the literature on adverse selection is based on theoretical analysis of contract design mechanisms to reduce incentive incompatibilities (Wu and Babcock, 1996, Moxey et al., 1999, Feng, 2007), but very few studies have actually empirically examined this information problem for agrienvironmental contracts. In this paper, the HLS contract design is taken as given, and instead emphasis is placed on the HLS contract allocation mechanism. In addition, this paper evaluates both theoretically and empirically the potential for reducing adverse selection, and therefore improving costeffectiveness, by explicit government selection from applicants based on environmental benefits and subject to a budget constraint on total payments to farmers. The next section develops a principalagent model to assess the potential for adverse selection reduction in the HLS at the regional level (as compared to a spatially uniform national policy), followed by empirical evidence of whether adverse selection has been reduced. The paper ends with a summary and conclusions.

\section{Methodology}

The analysis is based on a theoretical principal-agent model of optimal farmer participation relative to the social optimum, in relation to land heterogeneity both within and between 'regions', as developed by Fraser (2009). A principal-agent model is developed to analyse HLS contract allocation by the principal (Natural England), in relation to the potential effects of the adverse selection of farmers into the HLS, as well as the combination of policy mechanisms aimed at reducing adverse selection at the regional level and subject to the budget constraint. The reference point for assessing adverse selection reduction will be taken as a nationally uniform scheme (nationally-uniform payment rate and environmental benefit per hectare). The focus is restricted to those HLS options involving entering land into the Scheme, as these most directly compete with agricultural production. The following analysis is specified as a between-region comparison, "regions" here referring to the Joint Character Areas (areas of relatively homogenous environmental features and landscape), and which are within the same budget area.

Under this framework, farmers are considered as profit-maximisers in relation to supplying environmental goods and services, which consequently leads to their selection of lower agricultural value land for HLS entry (i.e. with the highest net returns to entering the Scheme in relation to fixed payments based on average agricultural foregone income). The principal (Natural England) is assumed to maximise social welfare (i.e. the environmental benefit (EB)) across regions subject to a budget constraint:

$$
\begin{aligned}
& \max _{Q} E B_{H L S}=\sum_{r} w_{r} \mathrm{eb} \cdot q_{r} \\
& \text { subject to the budget constraint: } \sum_{i, j, r} q_{i, j, r} p_{j, r} \leq \text { Total Budget }
\end{aligned}
$$

\footnotetext{
${ }^{1}$ Although the HLS can be seen as a budget-constrained auction, based on an environmental score, this theoretical analogy is not developed here. See Latacz-Lohmann and Schilizzi, 2005 and Connor et al., 2008 for more detailed discussions of auction systems. Also, a payments-by-results approach has been discussed as a theoretical alternative to the current specification of the HLS, but is not considered here (see Schwarz et al., 2008).
} 
$\mathrm{q}_{i, j, r}$ the quantity of environmental service for contract $\mathrm{i}$, option $\mathrm{j}$, and in region $\mathrm{r}$;

$p_{r, j}$ the regional payment rate for option $\mathrm{j}$ in region $r$ (national average foregone agricultural income adjusted for regional variations).

It is assumed that eb is a decreasing function of the quantity of land offered for entry into HLS: the more hectares entered into HLS, the lower the environmental benefit per hectare. For modelling purposes, the environmental benefit function is assumed the same within a given region (with the same landscape character) and across regions with its value depending only on the quantity of land entered into the Scheme (the consequences of relaxing this regional assumption are considered later in this analysis). However the weighted environmental benefit per hectare for a given region $\left(w_{r}\right.$ eb) varies across regions. By construction, $w_{r}$ eb also is a decreasing function of the quantity of land entered into HLS. This formalisation can be interpreted as capturing a uniform environmental non-use landscape value (i.e. scarcity and uniqueness of the environmental good) through the quantity of land entered into the Scheme, while the relative weighting can be interpreted as reflecting differential environmental use value of the land entered into the Scheme across regions. As such, the principal can be seen as attempting to capture the full social benefit from environmental goods and services provided by land entered into the Scheme (see Fleischer and Tsur, 2000, Hanley et al., 2003, Bateman et al., 2006, Brunstad et al., 1999, Hanley et al., 2007).

Under the stated assumptions and the budget constraint, the social-welfare (EB) maximising first-order condition under the budget constraint, after rearranging the terms, becomes:

$$
\begin{aligned}
& \sum_{r}\left(w_{r} \mathrm{eb} q_{r}\right) \frac{\partial \ln \left(q_{r}\right)}{\partial Q}-\lambda \sum_{i, j, r} q_{i, j, r} p_{j, r} \frac{\partial \ln \left(q_{i, j, r}\right)}{\partial Q} \\
& =\left[\lambda \sum_{i, j, r} q_{i, j, r} p_{j, r} \frac{\partial \ln \left(p_{j, r}\right)}{\partial Q}\right]-\left[\sum_{r} w_{r} \operatorname{eb} q_{r} \frac{\partial \ln \left(w_{r} \mathrm{eb}\right)}{\partial Q}\right]
\end{aligned}
$$

From equation 2, the marginal net environmental benefit for the principal from the land entered into HLS (left hand-side) can be decomposed into the net benefit obtained by varying the payment rates regionally (first term on the right hand-side) plus the net benefit obtained from the regional variation of environmental benefit per hectare between regions (second term on the right hand-side). The terms on the right-hand-side for equation 2 are equal to zero for a nationally uniform scheme (respectively nationally-uniform payment rates and environmental benefits per hectare). The marginal net environmental benefit for the principal from the land entered into HLS for a spatially differentiated Scheme consequently represents the cost-effectiveness gains from a reduction in adverse selection compared to a nationally uniform scheme (i.e. no explicit selection of contracts).

Following equation 2, the principal's objective function can be decomposed into 2 parts:

selection of $Q$ by varying $q_{r}$ between regions for different regional payment rates $p_{r, j}$ for a given constant weighted environmental benefit per hectare (constant $w_{r}$ ).

- selection of $Q$ by varying the weighted environmental benefit per hectare between regions $w_{r}$ eb for a given constant payment rate $\left(p_{r, j}\right)$.

Differentiating the welfare-maximising first order condition (equation 2) with respect to the regional payment rate $p_{r, j}$ for a given weighted environmental benefit per hectare ( $w_{r}$ constant across regions) leads, after rearranging, to:

$$
\frac{\partial \ln q_{r}}{\partial \ln p_{j, r}}=-1<0
$$

From equation 3, the total quantity of land $Q$ entered into the HLS maximising environmental benefit is such that, for each extra hectare of land entered into the Scheme, the proportion of land entered in each region is equal to the opposite of the proportional change in payment rates for the region (given the same weighted environmental benefit per hectare). This is equivalent to the following:

Hypothesis 1: For the same given HLS budget (and equal regional weights), the quantity admitted into HLS will be greater in regions with lower payment rates (reflecting lower foregone agricultural incomes).

This implies that, for the same environmental benefit derived from each hectare of land entered into the Scheme (i.e. assuming equal regional weights), for a given budget (ABEF=GCDF in Figure 1) 
there is an overall associated higher total environmental benefit (Figure 1: eb( $\left.q_{2}\right)>e b\left(q_{1}\right)$ by definition of eb as a decreasing function of $\mathrm{q}$ ) because more hectares can be contracted overall by contracting in lower payment regions (region 1 in Figure 1),. This has the effect of improving cost-effectiveness through the mechanism of the budget constraint. Note, however, that if environmental non-use value and the agricultural OC are negatively correlated (as suggested by Robinson and Sutherland, 2002, Hendrickx et al., 2007), regions with lower payment rates (reflecting lower foregone agricultural incomes) would also be those of high environmental non-use value. The increased entry of land in these regions would thus further increase the total environmental benefit (as illustrated in Fraser, 2009, Table 1) ${ }^{2}$.

\section{Figure 1: Comparison of land areas offered for entry between regions 1 and 2 with different} marginal opportunity costs (MOC) and payment rates (p), for the same budget (ABEF=GCDF)

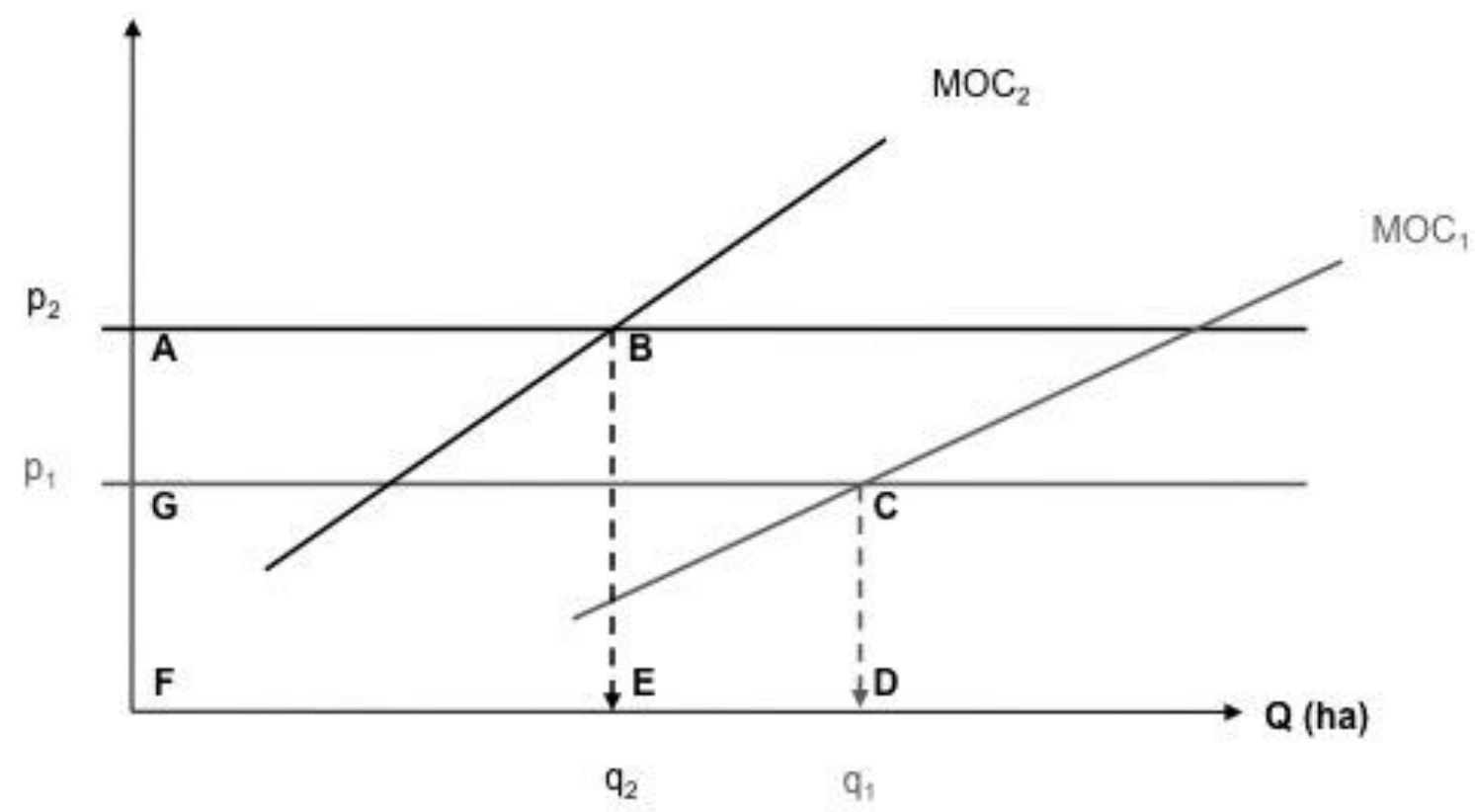

If one region displays a higher environmental benefit per hectare (i.e. the total willingness-to-pay per hectare is higher), the objective function can be adjusted to weight one region more highly (i.e. $w_{r}$ now varying across regions). Differentiating the welfare-maximising first order condition (equation 2) with respect to the weighted environmental benefit per hectare $w_{r}$ eb for given regional payment rates per option ( $p_{r, j}$ constant across regions) leads, after rearranging, to:

$$
\frac{\partial \ln \left(q_{r}\right)}{\partial \ln \left(w_{r} \mathrm{eb}\right)}=1>0
$$

From equation 4, the total quantity of land $Q$ entered into the HLS maximising environmental benefit is such that, for each extra hectare of land entered into the Scheme, the proportion of land entered in each region is equal to the proportion of (weighted) environmental benefit per hectare for that region (constant payment rates). This is equivalent to the following:

Hypothesis 2: For differing regional weights, the quantity of land contracted will be higher in the regions with higher weighted environmental benefit for the same regional fixed payment rates per hectare (i.e. similar agricultural foregone incomes).

\footnotetext{
2 The assumption of a uniform environmental benefit function can also be formally relaxed using the model in this paper. Consistent with the results in Fraser (2009), for the same given HLS budget the quantity of land contracted will be higher in the regions with higher environmental benefit per hectare for the same regional fixed payment rates per hectare (i.e. similar agricultural value). This modelling is available upon request.
} 
This implies that (for the same budget) regions with a higher weighted environmental benefit per hectare (region 1 in Figure 2) are likely to display a higher rate of land admitted into the HLS (from Figure 2: the entry of $q$ in region 1 is more likely to be chosen by the principal over the entry of $q$ in region 2, for the same budget, as it will lead to a greater weighted environmental benefit per hectare). This again has the effect of improving the cost-effectiveness of the Scheme, since the principal is choosing mainly farmers from the region with higher environmental benefit per hectare, thus achieving a higher total environmental benefit given the budget constraint.

Figure 2: Comparison of the weighted environmental value of the land offered for entry between regions 1 and 2, for the same marginal opportunity costs (MOC)

f/ha

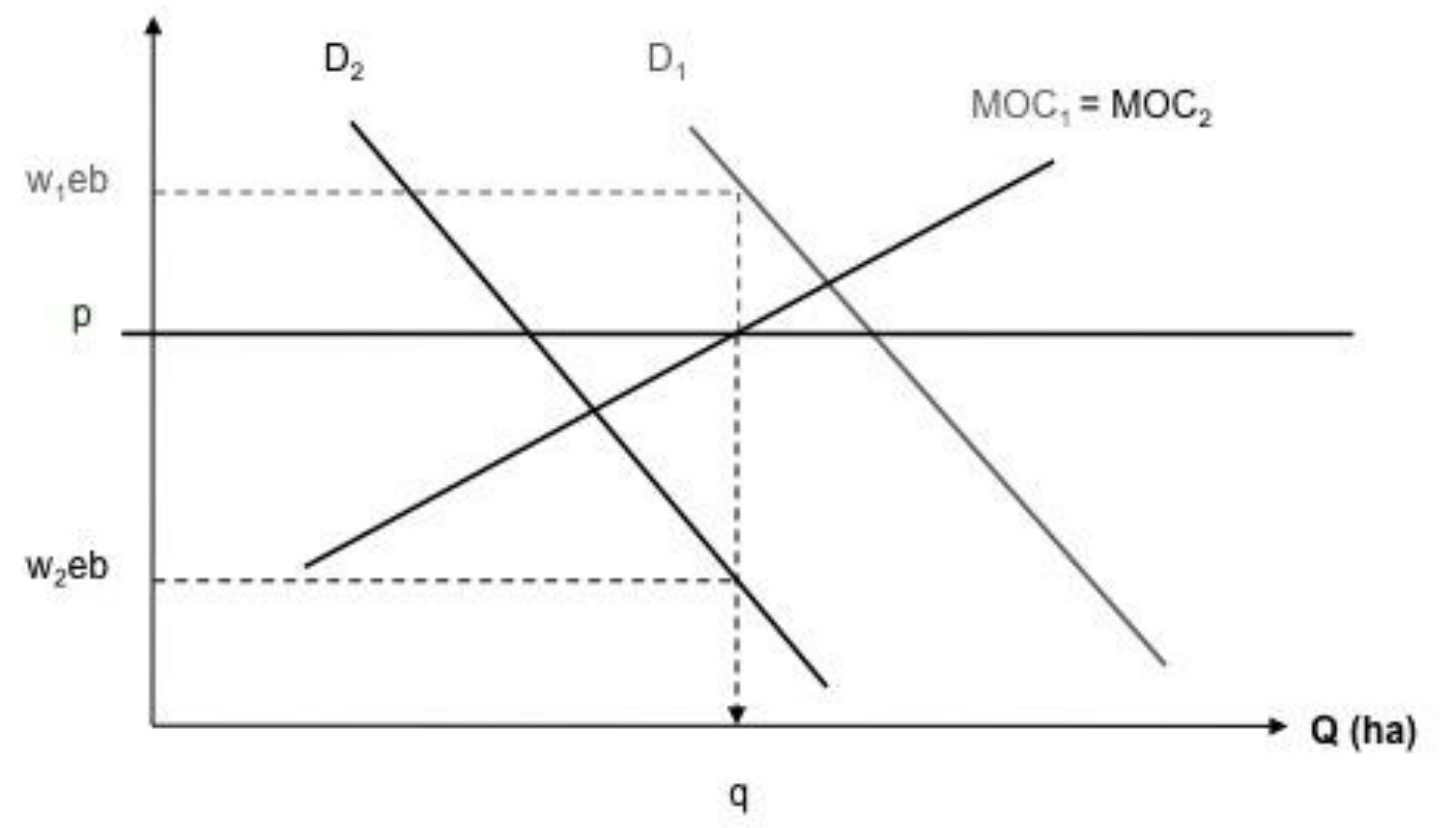

In the empirical evaluation, the differential regional weights have been proxied by distances to some of the main cities (with distance inversely related to environmental value in the principal's objective function), implying that the principal allocates for a given budget proportionately more contracts in regions closer to cities (i.e. with a higher environmental benefit per hectare) than in regions with similar agricultural OC but further from cities. For examples of this use (or recreation) value interpretation of distance see Fleischer and Tsur, 2000, Hanley et al., 2003, Bateman et al., 2006. The use of distance as a proxy for the environmental use value of agricultural land in HLS is also consistent with the explicit aim of the HLS to promote "public access and understanding of the countryside" (Defra, 2005b p.6; Thomson and Whitby, 1976, Boatman et al., 2008).

In summary, this general conceptualisation of the principal's contract allocation problem characterises the principal as choosing from applicants to the HLS based on an attempt to capture both environmental non-use value of the land entered (through the quantity of land entered), and environmental use value (through the distance to cities) ${ }^{3}$.

\section{Empirical evidence}

From the above analysis, evidence that adverse selection is being reduced, and cost-effectiveness thereby increased, would be a statistically significant link between the number of hectares entered into HLS in a given region and the associated regional payment rates (hypothesis 1), and with the distance to the main cities (hypothesis 2).

\footnotetext{
${ }^{3}$ We are grateful to our anonymous reviewers and the Associate Editor for pointing out this use and non-use value interpretation to us.
} 
Contract data for all Environmental Stewardship tiers were provided by Natural England for 9 landscape regions (Joint Character Areas) in the budget region of Yorkshire and the Humber, with some contract characteristics detailed at option-level and others at contract-level. Threshold score and budget were the same for the 9 Joint Character Areas, following the national design of the Scheme. The quantity of land entered into the HLS per contract (qland) and total payment received per contract for the land entered into HLS were summed for each contract for all HLS options (aggregation per contract). The average payment rate per contract was obtained by taking the ratio of the total payment received for all HLS options to the total quantity of land entered into HLS for each contract. Mappy.co.uk was used to estimate the fastest travelling distances to Hull (most Eastern city), Leeds and Manchester (respectively most central and South-Western city) as two of the biggest conurbations in Northern England (Defra, 2000) for each contract. An average of these 3 distances was then calculated for each contract: by construction, the greater the average distance, the further away from the major East-West travelling link in the study area. The data used have been summarised in Table 1.

Table 1: Variables description and statistics

\begin{tabular}{|c|c|c|c|c|c|c|}
\hline Variable & Description & Units & Mean & Std. Dev. & Min & Max \\
\hline qland & $\begin{array}{l}\text { quantity of land entered into the } \\
\text { HLS per contract }\end{array}$ & ha & 154 & 219 & 3 & 1,092 \\
\hline & $\begin{array}{l}\text { total payment received per } \\
\text { contract for the land entered } \\
\text { into HLS }\end{array}$ & $£$ & 100,308 & 118,705 & 2,991 & 564,984 \\
\hline avepr & $\begin{array}{l}\text { average payment rate per } \\
\text { contract }\end{array}$ & $£ /$ ha & 1,041 & 625 & 337 & 2,893 \\
\hline avedist & $\begin{array}{l}\text { Average of fastest travelling } \\
\text { distances to Hull Leeds and } \\
\text { Manchester }\end{array}$ & $\mathrm{km}$ & 117 & 23 & 70 & 171 \\
\hline
\end{tabular}

Log-linear regressions were performed using Stata 9 (StataCorp, 2005), by regressing the quantity of land entered into HLS (qland) over the payment rate per contract (avepr) and the average distance to the three main cities (avedist). The HLS data sample is truncated as HLS successful entrants are mostly selected from a population of farmers enrolling into the (O)ELS part of the Environmental Stewardship Scheme, and only operating HLS contract data were available. Both truncated and OLS regressions on the log-transformed variables for the given sample led to similar results, so the OLS results (log-linear model) only are reported in Table 2.

Table 2: Log-linear regression results for estimating the quantity of land entered into HLS. (*: significant at a $10 \%$ level; **: significant at a $5 \%$ level; ${ }^{\star \star *}$ : significant at a $1 \%$ level of significance)

\begin{tabular}{|c|c|}
\hline & Coefficients \\
\hline $\begin{array}{r}\text { avepr } \\
\text { (standard error) }\end{array}$ & $\begin{array}{l}-2.0^{* * *} \\
(0.3)\end{array}$ \\
\hline avedist & $-2.5^{* * *}$ \\
\hline & $(0.8)$ \\
\hline constant & $\begin{array}{l}29.5^{* * *} \\
(5.1)\end{array}$ \\
\hline $\mathbf{N}$ & 46 \\
\hline $\mathbf{R}^{2}$ & 0.52 \\
\hline Adjusted $\mathbf{R}^{2}$ & 0.49 \\
\hline $\begin{array}{l}\text { Breusch Pagan test } \\
\text { (heteroskedasticity) }\end{array}$ & \\
\hline Chi2 test statistic (1) & 0.21 \\
\hline P-value & 0.65 \\
\hline $\begin{array}{r}\text { d-statistic }(3,46) \\
\text { P-value }\end{array}$ & $\begin{array}{l}2.26 \\
0.65\end{array}$ \\
\hline
\end{tabular}


Under a given budget constraint and controlling for the weighted environmental benefit per hectare (distance to cities), the quantity of land entered is hypothesised to decrease for higher average payment rates (hypothesis 1). A negative coefficient for the average payment rate per contract is consequently expected in the regression analysis. With land closer to cities having a higher environmental value per hectare, for constant payment rates, the quantity of land entered is hypothesised to decrease as the distance from the main cities increases. A negative coefficient for the average distance to main cities is thus expected in the regression analysis (hypothesis 2).

The adjusted $\mathrm{R}^{2}$ value is relatively high (49\%) for cross-sectional data, possibly reflecting the fact that the sample is drawn from the same area with similar characteristics. All coefficients display the expected negative signs, and both the coefficients for average payment rates and for the average distance to main cities were found significant at $1 \%$. No heteroskedasticity was detected (BreuschPagan / Cook-Weisberg test: Chi2 test statistic $(1)=0.21 ; p$-value of 0.65$)$. First-order autoregressive errors $(A R(1))$ would be the most likely to arise for the spatially ordered data, but were not found statistically significant (Durbin-Watson d-statistic $(3,46)$ of 2.26 ).

As expected, the quantity of land entered significantly decreases as the payment rates increase (i.e. increasing foregone agricultural incomes) providing evidence that, for a given environmental non-use benefit per hectare, more land is enrolled into the HLS in lower payment regions (hypothesis 1). Therefore, for a given budget, and given the same environmental non-use benefit per hectare for all regions, more land overall will be entered into the HLS across all regions from lower payment areas, resulting in a higher total environmental benefit from the Scheme, and an associated increase in the cost-effectiveness of the Scheme.

Also as expected, the quantity of land entered is negatively related to the average distance to main cities, i.e. a decreasing quantity of land is entered for decreasing environmental value. Therefore, there is some evidence that, for regions with the same payment rate (i.e. same agricultural land value) but varying environmental benefit weights (represented by distance to the main cities), more land is enrolled into the HLS from areas of higher environmental benefit (i.e. closer to the main cities) under a given budget constraint (hypothesis 2). Provided that the distance to the main cities (capturing use value) is a good indicator of environmental value as assumed in this case, HLS contract allocation seems to reflect some differentiating of environmental use value by region, and therefore increased cost-effectiveness of the Scheme.

\section{Conclusion}

The Environmental Stewardship Scheme, because of incentive incompatibility and asymmetric information, has the potential for adverse selection for the land entered into the Scheme, leading to reduced cost-effectiveness of the Scheme. However, we hypothesise that adverse selection into its HLS component could be reduced by the explicit selection of contracts based on environmental use and non-use benefit criteria embedded into the HLS policy design, combined with the operation of a total payment budget constraint. To evaluate these hypotheses our empirical research focuses on Scheme selection allowing both for the impact of spatially differentiated payment rates (reflecting differentiated costs of foregone agricultural income of entering HLS) in the context of uniform environmental non-use benefits, and for differentiated environmental use benefits per hectare (inversely related to distances to main cities) as design mechanisms operating to reduce adverse selection and thereby increase cost-effectiveness.

The results show that differences in payment rates between two regions are significantly negatively related to the amount of land admitted into the Scheme for each landscape region. This provides evidence of the capturing of increased environmental non-use benefits by exploiting spatial differentiation of payment rates, thereby reducing adverse selection, and thus increasing Scheme cost-effectiveness. In addition, differences in environmental benefit weights between regions (as measured by travelling distance to cities) were found to be significantly negatively related to the amount of land admitted into the Scheme for each landscape region. For landscape regions with the same payment rates (i.e. of the same agricultural value), differential weighting of the public use benefit from environmental goods and services provided by agriculture (as measured here) thus appears to be reflected into the regulator's allocation of contracts, thereby also reducing the adverse selection problem and increasing the Scheme's cost-effectiveness.

Further research could control for parish income or population, as these could be expected to influence the willingness-to-pay for conservation (Brunstad et al., 1999). In addition, the Scheme's 
operation and allocation mechanisms were revised in 2008, with applications targeted spatially within the same administrative region, with an increased budget. As a result, it would be interesting to analyse contract allocation from 2008, in order to further assess the role of the budget constraint as a mechanism involved in increasing Scheme cost-effectiveness.

\section{References}

Boatman, N. D., C. Ramwell, H. Parry, N. Jones, J. Bishop, P. Gaskell, C. Short, J. Mills and J. Dwyer (2008). A Review of Environmental Benefits Supplied by Agri-Environmental Schemes. FST20/79/041. Land Use Policy Group.

Bateman, I. J., B. H. Day, S. Georgiou, I. Lake (2006). The aggregation of environmental benefit values: Welfare measures, distance decay and total WTP. Ecological economics, 60(2), 450-460.

Brunstad, R. J., I. Gaasland and E. Vardal (1999). Agricultural Production and the Optimal Level of Landscape Preservation. Land Economics, 75(4), 538-546.

Connor, J. D., J. R. Ward and B. Bryan (2008). Exploring the cost effectiveness of land conservation auctions and payment policies. Australian Journal of Agricultural and Resource Economics, 52(3), 303-319.

Defra (2000). Yorkshire and the Humber: Geographic Area and Physical Context. Department for Environment, Food and Rural Affairs. Edition: 01/10/2000. Last updated: 17/08/2005. Available from: http://www.defra.gov.uk/erdp/docs/yhchapter/yhsection11/default.htm [Accessed 22/09/2008].

Defra (2005a). Environmental Stewardship: Look after your land and be rewarded.

PB10487.Department for Environment, Food and Rural Affairs. Available from: http://www.defra.gov.uk/erdp/schemes/es/default.htm [Accessed 06/07/2007].

Defra (2005b). Higher Level Stewardship handbook: Terms and conditions and how to apply. PB10382.Department for Environment, Food and Rural Affairs. Available from: http://www.defra.gov.uk/erdp/pdfs/es/hls-handbook.pdf [Accessed 22/06/2007].

Feng, H. (2007). Green payments and dual policy goals. Journal of Environmental Economics and Management, 54(3), 323-335.

Fleischer, A. and Y. Tsur (2000). Measuring the recreational value of agricultural landscape. European Review of Agricultural Economics, 27(3), 385-398.

Fraser, R. (2009). Land Heterogeneity, Agricultural Income Forgone and Environmental Benefit: An Assessment of Incentive Compatibility Problems in Environmental Stewardship Schemes. Journal of Agricultural Economics, 60(1), 190-201.

Fraser, R. and I. Fraser (2006). "The Implications of Information Asymmetries for Agri-Environmental Policies". Paper presented to the OECD Workshop on Information Deficiencies in Agri-environmental Policies, Paris, June. Available from: www.oecd.org/agr/meet/idap.

Hanley, N., F. Schläpfer and J. Spurgeon (2003). Aggregating the benefits of environmental improvements: distance-decay functions for use and non-use values. Journal of Environmental Management, 68(3), 297-304.

Hanley N., S. Colombo, P. Mason, and H. Johns (2007) The reform of support mechanisms for upland farming: paying for public goods in the Severely Disadvantaged Areas of England. Journal of Agricultural Economics, 58 (3), 433-453.

Hendrickx, F., J. Maelfait, W. Van Wingerden, O. Schweiger, M. Speelmans, S. Aviron, I. Augenstein, R. Billeter, D. Bailey, R. Bukacek, F. Burel, T. I. M. Diekotter, J. Dirksen, F. Herzog, J. Liira, M. Roubalova, V. Vandomme and R. O. B. Bugter (2007). How landscape structure, land-use intensity and habitat diversity affect components of total arthropod diversity in agricultural landscapes. Journal of Applied Ecology, 44(2), 340-351. 
Latacz-Lohmann, U. and S. Schilizzi (2005). Auctions for Conservation Contracts: A Review of the Theoretical and Empirical Literature. Project No: UKL/001/05. Available from:

http://www.scotland.gov.uk/Resource/Doc/93853/0022574.pdf [Accessed 14/01/2008].

Mappy.co.uk. Mappy SA. Available from: http://mappy.co.uk/ [Accessed 11/11/2008 \& 15/01/2009].

Moxey, A., B. White and A. Ozanne (1999). Efficient contract design for agri-environment policy. Journal of Agricultural Economics, 50(2), 187-202.

OECD (2004). Agriculture and the environment: lessons learned from a decade of OECD work. Available from: http://www.oecd.org/dataoecd/15/28/33913449.pdf [Accessed 25/06/2007].

Robinson, R. A. and W. J. Sutherland (2002). Post-war changes in arable farming and biodiversity in Great Britain. Journal of Applied Ecology, 39(1), 157-176.

StataCorp (2005). Stata Statistical Software: Release 9. College Station, TX: StataCorp LP.

Wu, J. and B. A. Babcock (1996). Contract Design for the Purchase of Environmental Goods from Agriculture. American Journal of Agricultural Economics, 78(4), 935-945.

Schwarz, G., A. Moxey, D. McCracken, S. Huband and R. Cummins (2008). An analysis of the potential effectiveness of a Payment-by-Results approach to the delivery of environmental public goods and services supplied by Agri-Environment Schemes. Report to the Land Use Policy Group, UK, 108pp. Macaulay Institute, Pareto Consulting and Scottish Agricultural College.

Thomson, K. J. and M. C. Whitby (1976). The Economics of Public Access in the Countryside. Journal of Agricultural Economics, 27(3), 307-320. 